References

' Garland H, Pearce J. Neurological complications of carbon monoxide poisoning. $Q J$ Med 1967;36:445-85.

${ }^{2}$ Smith JS, Brandon S. Morbidity from acute carbon monoxide poisoning at three year follow-up. Br Med J 1973;i:318-21.

${ }^{3}$ Ames A III, Wright RL, Kowade M, Thurston M, Majno G. Cerebral ischemia, II, the no re-flow Phenomenon. Am J Pathol 1968;52:437-54.

4 Chiang J, Kowade M, Ames A III, Wright RL, Majno G. Cerebral ischemia, III, vascular changes. Am J Pathol 1968;52:455-65.

\section{Morbidity in patients with intracranial gliomas}

Sir: In 1980 the factors affecting mortality in patients with cerebral gliomas were considered. ${ }^{1}$ Individual prognostic factors which were found to be associated with longer survival from first symptoms were a younger age, epilepsy as a presenting feature, a grade of glioma less than IV (glioblastoma multiforme), partial removal of the tumour, radiotherapy and chemotherapy. Although survival is important, the quality of life is equally, if not more so. A problem is to decide whether the benefits of active investigation and treatment (operation, radiotherapy and chemotherapy) outweigh the discomfort, morbidity and mortality of the procedures. Many patients near death would prefer, if possible to be at home rather than spend their last few weeks in hospital. We studied the morbidity of the disease in 110 patients with histologically proven gliomas who attended between 1961 and 1977. One hundred and four patients were followed up until 1981 or until death, but six were still alive when last seen and are now lost to follow up. Of these 110, 42 had Grade III, 39 Grade IV and 18 Grade I and II astrocytomas. The remaining 11 had other gliomas. This population of patients is heterogeneous in respect of possible prognostic factors, but we think represents a typical population of patients with gliomas.

Morbidity was assessed retrospectively until 1976 and then prospectively. A simplified rating scale based on that of Karnofsky and Burchenal ${ }^{2}$ was used. The categories used were full function (Scale 90-100), independent (70-80), dependent but at home (40-60) or in hospital (1030).

The prognosis in terms of the morbidity rating at first symptoms, on first admission to hospital or at the time of operation was studied and, as expected, showed that

Table Quality of life for the 70 patients surviving more than 5 months

\begin{tabular}{|c|c|c|c|c|c|c|}
\hline Morbidity & At $5 \mathrm{mth}$ & At $1 y r$ & At $2 y r$ & At $3 y r$ & At $4 y r$ & At $8 y r$ \\
\hline $\begin{array}{l}\text { Alive } \\
\text { Full function } \\
\text { Independent } \\
\text { At home, dependent } \\
\text { In hospital } \\
\text { Dead } \\
\text { Alive at final assessment } \\
\text { but lost to follow-up or } \\
\text { follow-up too short }\end{array}$ & $\begin{array}{l}13 \\
16 \\
27 \\
14 \\
-\end{array}$ & $\begin{array}{r}10 \\
9 \\
10 \\
2 \\
33\end{array}$ & $\begin{array}{r}8 \\
8 \\
4 \\
1 \\
41\end{array}$ & $\begin{array}{r}5 \\
4 \\
6 \\
1 \\
46\end{array}$ & $\begin{array}{r}4 \\
3 \\
4 \\
-50\end{array}$ & $\begin{array}{r}3 \\
1 \\
0 \\
55\end{array}$ \\
\hline
\end{tabular}

those with low morbidity had a good early prognosis. However, these data did not give a realistic evaluation of long-term morbidity. In the table, therefore, the morbidity of 70 patients $(64 \%)$ who survived five months from first symptoms (and would on the whole have completed operative and treatment procedures) is shown at each year after first symptom in relationship to survival. The data show that very few patients who survive five months are unable to live at home and that the majority of those who survive can lead independent lives, often with full function. Very few patients get trapped in the tragic situation of being in hospital or requiring prolonged care from relatives. In this, they are luckier than patients following severe head injuries or strokes.

The data also indicate that the prognosis for patients with primary brain tumours is bad. The mode of onset of disease was reviewed by McKern and Thomas, ${ }^{3}$ but morbidity between time of diagnosis, operation or death was not considered. In this study, patients who did survive often led a relatively normal life for a long time. When their condition deteriorated, their decline tended to be rapid. There is no evidence that operation or treatment in the first five months could, in themselves, leave a patient in a prolonged state of disability, although the immediate morbidity due to these procedures is impossible to assess.

In summary, the mortality in a group of 110 patients with gliomas was high. However those who survived the first few months led a relatively normal life for a reasonable time. When their condition deteriorated decline was rapid and they rarely remained long in the situation of needing considerable care. These results should encourage doctors to treat patients with gliomas.

FB GIBBERD

GM SCOTT

The Neurology Department, The Westminster Hospital, Horseferry $R d$, London SWIP 2AP, UK

\section{References}

' Scott GM, Gibberd FB. Epilepsy and other factors in the prognosis of gliomas. Acta Neurol Scand. 1980;61:227-39.

${ }^{2}$ Burchenal JH. The clinical evaluation of chemotherapeutic agents. In: McLeod, ed, The Evaluation of Chemotherapeutic Agents. New York: Columbia University Press 1949 : 161-205.

${ }^{3}$ McKern RD, Thomas DGT. The clinical study of gliomas. In: Thomas DGT, Graham DI, eds. Brain Tumours. London, Butterworth, 1980: $194-230$.

Trigeminal and facial nerve involvement resulting from ischaemia of the petrosal branch of the middle meningeal artery

Sir: We describe a woman with diabetes mellitus who suddenly experienced total facial paralysis on the right side accompanied by ipsilateral anaesthesia in the reg ion of the trigeminal nerve. It is speculated, on the basis of anatomical, experimental and clinical data, that this association resulted from a vascular mechanism involving the petrosal branch of the middle meningeal artery. Thus the present case report may also provide some clues as to the aetiology of idiopathic facial paralysis.

A 56-year-old woman with mild hypertension and diabetes mellitus was admitted in November 1979 following the sudden onset of facial weakness and paraesthesiae confined to the right side of the face. On admission, blood pressure was 160/ $95 \mathrm{~mm} \mathrm{Hg}$, and neurological examination revealed complete right-sided peripheral facial palsy and loss of sensation over the whole distribution of the right trigeminal nerve, with striking impairment of appreciation of pain and temperature. The corneal reflex was absent while the Vth nerve motor function was preserved. Funduscopic examination showed microaneurysms, soft exudates, and narrowing of the retinal vessels. All laboratory tests were unremarkable except for an increased blood glucose level. The EEG, radiographs and CT scan of the skull, radiographs of the chest and cervical spine, full audiometric 
and vestibular function tests, right vertebral angiography, and lumbar puncture showed no abnormalities. Electromyographic studies revealed complete functional denervation of the right facial nerve and mild abnormalities of nerve conduction in the lower limbs.

Spontaneous recovery began from the day of admission. Recovery of the function of the muscles supplied by the facial nerve paralleled recovery of sensory loss over the region of the trigeminal nerve distribution. No evidence of involvement of the $V$ th and VIIth cranial nerves was detected 1 month later.

Diabetes mellitus is prone to damage the vascular system by causing atherosclerosis and microangiopathy; such vascular disturbances may play a significant role in the development of diabetic cranial neuropathies, which have an abrupt onset and improve spontaneously. ${ }^{12} \mathrm{~A}$ high incidence of diabetes mellitus in patients presenting with Bell's palsy has been reported $^{3-5}$ and some of these cases have been regarded as a diabetic mononeuropathy. ${ }^{6}$ In our patient, diabetes mellitus was probably responsible for the sudden involvement of the Vth and VIIth cranial nerves. A vascular mechanism for this unusual association may be proposed on the basis of a common arterial supply of the Vth and VIIth cranial nerves. It is known that the petrosal branch of the middle meningeal artery supplies the horizontal segment and geniculate ganglion of the facial nerve as well as the ganglion of Gasser. ${ }^{7}$ Calcaterra $e t a^{8}$ and Lasjaunias et $a l^{9}$ each reported a patient with abrupt paralysis of the VIIth and Vth cranial nerves resulting from experimental embolisation of the middle meningeal artery for preoperative treatment of an intracranial tumour. There were striking similarities in the symptomology and clinical evolution between their patients and our patient.

The association of peripheral facial nerve palsy with objective sensory involvement of the Vth nerve is most commonly due to a progressive spaceoccupying lesion. However, a trigeminal involvement has been repeatedly observed in the course of Bell's palsy. ${ }^{10}{ }^{11}$ Lapresle $e t$ $a^{10}$ first proposed a vascular basis for the simultaneous trigeminal sensory involvement occurring in some cases of Bell's palsy and our findings in a case of diabetes mellitus may also be explained by a vascular mechanism. Other possible hypotheses (including an infective aetiology ${ }^{11}$ or variants of sensory innervation of the face) seem unlikely. In fact, in our patient, some features of the cranial neuropathy, such as the abrupt onset and the simultaneous and progressive recovery from involvement of both the Vth and VIIth cranial nerves, strongly suggest a common vascular aetiological factor for this association, which is very likely to be related to diabetes mellitus.

We conclude that sudden involvement of both the Vth and VIIth cranial nerves implies a vascular mechanism within the petrosal branch of the middle meningeal artery, and partial or complete recovery should be expected.

ROBERTO MICHELUCCI, M.D. ALBERTO FORTI, M.D. ROBERTO DE MARIA, M.D. MARIO AMORE, M.D. CARLO ALBERTO TASSINARI, M.D. The Neurological Clinic,

University of Bologna School of Medicine, Via Ugo Foscolo 7, 40123 Bologna, Italy

\section{References}

' Diamond G, Frew I. The facial nerve. Oxford: Oxford University Press, 1979:110-2.

${ }^{2}$ Asbury AK, Johnson PC. Diabetic Neuropathy in Pathology of Peripheral Nerve. Philadelphia: WB Saunders, 1978:96-109.

${ }^{3}$ Korezyn AD. Bell's palsy and diabetes mellitus. Lancet 1971;1:108-10.

${ }_{4}^{4}$ Adour KK, Wingerd J, Doty HE. Prevalence of concurrent diabetes mellitus and idiopathic facial paralysis (Bell's palsy). Diabetes 1975;24:449-51.

s Lundgren A, Adkvist LM, Hendriksson KG, Lavsson LE, Karlberg BE, Jervall L. Facial palsy in diabetes mellitus-not only a mononeuropathy? Adv Otorhinolaryngol. 1977;22:182-9.

- Pecket P, Schattner A. Concurrent Bell's palsy and diabetes mellitus: a diabetic mononeuropathy? J Neurol Neurosurg Psychiatry 1982;45:652-5.

' Blunt MJ. The blood supply of the facial nerve. $J$ Anat 1954;88:520-5.

${ }^{8}$ Calcaterra TC, Rand RW, Bentson JR Ischemic paralysis of the facial nerve: a possible etiologic factor in Bell's palsy. Laryngoscope 1976;86:92-7.

' Lasjaunias P, Doyon D, Edouard A. Les paralysies faciales périphériques postembolisation. Rapport sur un cas, discussion, prévention. Ann Otolaryngol 1978;95:595-602.

${ }^{10}$ Lapresle J, Fernandez Manchola I, Lasjaunias P. L'atteinte trigéminale sensitive au cours de la paralysie faciale périphérique essentielle. Nouv Presse Med 1980;9:291-3.

" Adour KK, Byl FM, Hilsinger RL, Kahn ZM, Sheldon MI. The true nature of Bell's palsy: analysis of 1000 consecutive patients. Laryngoscope 1978;88:787-801. 